\title{
Comparison of outcomes between intra-articular tranexamic acid versus intravenous tranexamic acid in unilateral knee joint replacement
}

\author{
M umraiz $\mathrm{N}$ aqshaband ${ }^{1}$, M uhammad T aqi ${ }^{2}$, Sohail Ashraf ${ }^{3}$, Faisal M asood ${ }^{4}$, M uhammad Akhtar ${ }^{5}$, M uhammad \\ Jazib $\mathrm{N}$ adeem ${ }^{6}$, Javaid $\mathrm{H}$ assan $\mathrm{R} \mathrm{aza}^{7}$, Rana D ilawaz $\mathrm{N}$ adeem ${ }^{8}$ \\ ${ }^{1}$ Assistant Professor, Department of O rthopedic Surgery, King Edward M edical U niversity / M ayo Hospital, L ahore. ${ }^{2}$ PGR, D epartment of \\ O rthopedic Surgery, K ing E dward M edical U niversity / M ayo H ospital, L ahore. ${ }^{3}$ Senior Registrar, M ayo H ospital, L ahore. ${ }^{4}$ Associate Professor, \\ D epartment of O rthopedic Surgery, M ayo H ospital, L ahore. ${ }^{5}$ Associate Professor, D epartment of O rthopedic Surgery, M ayo H ospital, L ahore. \\ ${ }^{6}$ Research Assistant, D epartment of O rthopedic Surgery, M ayo H ospital, L ahore. ${ }^{7}$ Research Assistant, D epartment of O rthopedic Surgery, M ayo \\ H ospital, L ahore. ${ }^{8}$ Professor, D epartment of O rthopedic Surgery, K ing E dward M edical U niversity / M ayo H ospital, L ahore. \\ Correspondence to: D r. M uhammad T aqi, E mail: dr.taqi227@gmail.com
}

\begin{abstract}
Background: The goal of this research was to assess the effectiveness and safety of intra-articular tranexamic acid (T A) with intravenous (IV) T A in reducing perioperative blood loss, the severity of early postoperative problems, and venous thromboembolism in patients who have had a primary unilateral cemented total knee replacement.

Patients and methods: This comparative study was undertaken using a non-probability purposive sampling technique at the Department of O rthopedic Surgery, King Edward M edical U niversity / Mayo Hospital, Lahore, from July $1^{\text {st, }} 2018$ to 0 ctober $30^{\text {th, }} 2019$. A total of number 71 patients, aged 35 to 75 years, who underwent unilateral cemented total knee replacement for advanced knee osteoarthritis were included in the study. Patients who had known allergic reactions to tranexamic acid, risk factors of thromboembolism, severe kidney and heart diseases, and blood clotting disorders were excluded. The patients were divided into two groups, A and B. Preoperatively, patients in Group A were given intraarticular tranexamic acid $(3000 \mathrm{mg}$ ). In Group B, intravenous tranexamic acid $(10 \mathrm{mg} / \mathrm{kg})$ was given pre-operatively. O utcome parameters studied were drained blood $(\mathrm{D} \mathrm{B})$, level of hemoglobin $(\mathrm{Hb}$ ), blood transfusion (BT), and hematocrit $(\mathrm{H} \mathrm{ct})$ after 48 hours of surgery and compared with the preoperative value. Data was entered and analyzed using SPSS version 21.0. Independent sample T -test was applied to compare the hematocrit and hemoglobin difference in the two groups, and the P-value was taken less than 0.05 as significant.

Results: $O$ ut of the total 36 patients in G roup A, there were 20 (55.5\%) males and $16(44.4 \%)$ females, while amongst 35 patients in Group B, there were $21(60 \%)$ males and $14(40 \%)$ females. The mean preoperative $\mathrm{H}$ aemoglobin $(\mathrm{H} \mathrm{b})$ in $\mathrm{Group} A$ was $13.9 \pm 1.2$ and $13.8 \pm 0.9$ in $\mathrm{G}$ roup $B(p=0.44)$. T he mean postoperative $H \mathrm{~b}$ in $\mathrm{G}$ roup $A$ was $12.11 \pm 2.47$ and $11.24 \pm 3.52$ in Group B $(p=0.002)$. The mean variation of $H$ ct in G roup A was 4.49 and 6.82 in $G$ roup $B(p=$ $0.001)$.

Conclusion: Intra-articular tranexamic acid during total knee joint replacement is a viable alternative to the established intravenous tranexamic acid with statistically significant high postoperative hemoglobin and hematocrit levels.

Keywords:
\end{abstract}

Intra-articular tranexamic acid, Intravenous tranexamic acid, K nee arthroplasty, E ffectiveness

\section{INTRODUCTION}

Total knee replacement surgery is related to a significant amount of blood loss. N oticewala et al. conducted cohort research with 104 males (16\%) and 540 women (84 percent). T he average age was 67.6 years and 10.1 years (18-94 years), respectively. The results showed that $11 \%$ of the patients operated on for unilateral total knee replacement require subsequent blood transfusions. ${ }^{1,2}$ This increases the risk

\footnotetext{
C onflict of interest: T he authors declared no conflict of interest exists.

Citation: N aqshaband M, M asood F, T aqi M, Ashraf S, Akhtar M, N adeem

MJ, et al. Comparison of outcomes between intra-articular tranexamic acid versus intravenous tranexamic acid in unilateral knee joint replacement. J

Fatima Jinnah M ed U niv. 2021; 15(2):76-80.
}

D OI: https://doi.org/10.37018/EXBO 5236 of blood transfusion-related complications such as the transmission of infection, fluid overload, and blood reactions. ${ }^{3} D$ ifferent methods to decrease the need for blood transfusion have been described, which include injection of erythropoietin before the operation, use of iron supplements, intraoperative use of tourniquet, plasma rich concentrate, fibrin glue, and pharmacological agents that act as antifibrinolytic (tranexamic acid) used intraoperatively to decrease blood loss. ${ }^{4} \mathrm{~T}$ ranexamic acid (TXA), which works as an inhibitor of fibrinogen activity of plasma was first described in 1995 for use intraoperatively in controlling bleeding in primary total knee replacement. ${ }^{5,6}$ Since then, many clinical trials have been done to assess the effectiveness of tranexamic acid. ${ }^{6,7}$ There is a known 
increased risk of a thromboembolic event when used intravenously in patients with chronic renal failure and those with known previous ischaemic events and heart disease. $^{8}$

Intra-articular (IA) administration provides a maximum concentration at the bleeding site with limited systemic influence. ${ }^{9} \mathrm{~A}$ consensus regarding the optimal route of administration of tranexamic acid to control bleeding intraoperatively, with the least complications, is still debated. T his study aims to assess the effectiveness of intraarticular use of tranexamic acid to the established intravenous route in the control of bleeding postoperatively and reduction of thromboembolic complications in primary unilateral total knee replacements. ${ }^{10}$

\section{PATIENTS AND METHODS}

This comparative study was undertaken using a non-probability purposive sampling technique at the Department of Orthopedic Surgery, King Edward Medical U niversity $\backslash M$ ayo Hospital,

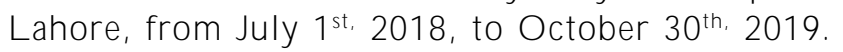
The sample size was 71 cases. Patients aged 35 to 75 years with advanced knee osteoarthritis who underwent unilateral cemented total knee replacement were included. Patients who had known allergic reactions to tranexamic acid, risk factors of thromboembolism, severe kidney and heart diseases, and blood clotting disorders were excluded. Ethical approval was taken from the hospital ethical review board. The patients were enrolled in the study after a thorough informed consent process, with the purpose of the study explained to them. The patients were randomized into Group A and Group B with binary envelope allocation. Four senior surgeons performed the procedures in a standardized manner. Preoperatively, Patients in Group-A were given intraarticular tranexamic acid $3000 \mathrm{mg}$ in $50 \mathrm{ml}$ of normal saline after cementing.
After 10 minutes of drug administration, the wound was closed without further flushing. W hile in Group B, Intravenous tranexamic acid 10 mg per $\mathrm{kg} 20$ was given before the skin incision and repeated during the wound closure. All patients received the same protocol for every patient.11-14 All operations were performed under spinal anesthesia using a midline skin incision with a medial parapatellar approach. Tourniquets were used only for a short time while cementing, intramedullary jig used for femoral cuts, and extramedullary jig for tibial cut used. Active drain placed in all patients for first 48 hours of operation and antibiotics prophylaxis along with thromboembolic prophylaxis by low molecular weight heparin $(1 \mathrm{mg} / \mathrm{kg})$ subcutaneously 12 hours after total knee replacements were given in all patients for 14 days. The characteristics of the individual group were based on body mass index, mean age of patients, male to female ratio, preoperative hemoglobin, American society of anesthesia grades (ASA), and hematocrit level. Parameters studied were the amount of drained blood, level of hemoglobin, and hematocrit after 48 hours of surgery and compared with preoperative value. The need for blood transfusion was determined according to an institutional policy of hemoglobin levels below $8 \mathrm{~g} / \mathrm{dl}$. T he Doppler scan for deep vein thrombosis was done in symptomatic patients (Calf pain \& Lower limb swelling). Complete blood count ( $C B C$ ) was also measured on the $2^{\text {nd }}$ day after the operation of primary total knee replacements. 12 hours after no addition, drains were removed, and patients were discharged. Patients were called for follow-up at 14 days, 42 days, and 56 days. Data was entered and analyzed using SPSS version 21.0. Independent sample $T$-test was applied to compare the hematocrit and hemoglobin difference in the two groups, and the $p$ value was taken less than 0.05 as significant.

\section{RESULTS}

O ut of the total 36 patients in G roup A, there were 20 $(55.5 \%)$ males and $16(44.4 \%)$ females, while amongst

Table 1. D emographics of the patients

\begin{tabular}{|c|c|c|c|}
\hline D emographics & $\begin{array}{c}\begin{array}{c}G \text { roup } A \\
(n=36)\end{array} \\
\end{array}$ & $\begin{array}{c}\text { G roup B } \\
(n=35)\end{array}$ & p-value \\
\hline Age (years) & $55 \pm 6.2$ & $52.9 \pm 6.7$ & 0.07 \\
\hline Gender & & & 0.06 \\
\hline M ale & 20 & 16 & \\
\hline Female & 21 & 14 & \\
\hline Body mass index & $31.1 \pm 4.7$ & $31.9 \pm 4.7$ & 0.3 \\
\hline ASA grade scale & $2.5+0.6$ & $2.3+0.5$ & 0.06 \\
\hline Preoperative hemoglobin $\mathrm{H} \mathrm{b}$ & $13.9 \pm 1.2$ & $13.8 \pm 0.9$ & 0.44 \\
\hline Preoperative hematocrit H ct & 39.94 & 40.21 & 0.698 \\
\hline \multicolumn{4}{|l|}{ Limb side } \\
\hline Right & 24 & 25 & 0.06 \\
\hline L eft & 12 & 10 & \\
\hline
\end{tabular}


Table 2. Postoperative comparison after total knee joint replacement

\begin{tabular}{lcc}
\hline \multicolumn{1}{c}{ Postoperative } & G roup A & G roup B \\
\hline H aemoglobin mean (grams) & $12.11 \pm 2.47$ & $11.24 \pm 3.52$ \\
\hline H ematocrit (H ct) & $34.37 \pm 3.1$ & $32.59 \pm 2.2$ \\
\hline Average time minutes & $92.5 \pm 13.7$ & 0.002 \\
\hline Average blood loss millimeters & $210 \pm 20$ & $96.69 \pm 12.3$ \\
\hline D eep vein thrombosis & 00 & $250.65 \pm 24.5$ \\
\hline
\end{tabular}

35 patients in Group B, there were $21(60 \%)$ males and $14(40 \%)$ females. The mean age of the patient in Group $A$ was $55 \pm 6.2$ years and $52.9 \pm 6.7$ years in Group B. L eft-sided total knee joint replacement was done in $40(56.3 \%)$ patients and $31(44.3 \%)$ had a rightsided total knee joint replacement. T he mean operative time of surgery in G roup A was $92.5 \pm 13.7$ minutes, and in $G$ roup $B$ was $96.69 \pm 12.3$ minutes ( $p$-value 0.06 ). A $210 \pm 20 \mathrm{ml}$ blood loss was calculated in Group $A$ through drainage bottle, and in $G$ roup $B$, blood loss was $250.65 \pm 24.5 \mathrm{ml}$ (T able 1). G roup A's mean preoperative $\mathrm{H}$ emoglobin $(\mathrm{H}$ b) was $13.9 \pm 1.2$ and $13.8 \pm 0.9$ in $\mathrm{G}$ roup B $(p=0.44)$. T he mean postoperative $\mathrm{Hb}$ in $\mathrm{G}$ roup $A$ was $12.11 \pm 2.47$ and $11.24 \pm 3.52$ in Group $B$ $(p=0.002)$. T he mean preoperative $\mathrm{H}$ ematocrit $(\mathrm{H} \mathrm{ct})$ in Group A was 39.94 and 40.21 in Group B $(p=0.698)$. T he mean postoperative $\mathrm{H}$ ct in $\mathrm{G}$ roup 1 was 34.37 and 32.59 in $\mathrm{G}$ roup $2(p=0.003)$. T he mean variation of $\mathrm{H}$ ct in $\mathrm{G}$ roup $A$ was 4.49 and 6.82 in $\mathrm{G}$ roup $B(p=0.001)$ (T able 2). The mean numbers of blood transfusions in Group A were two blood transfusions in 2 patients compared to five blood transfusions in 4 patients in Group B. W e observed no complications at follow-up of 2 weeks in Group A, while four cases of deep vein thrombosis were developed in Group $B$. $T$ hese patients were treated with oral anticoagulants. $\mathrm{N}$ o case of venous thromboembolism was noted in Group A. W hile comparing groups in terms of mean age, body mass index, preoperative $\mathrm{H} \mathrm{ct} / \mathrm{H} \mathrm{b}$, American Society of Anesthesiologists grade (ASA) grade, there were no statistical differences.

\section{DISCUSSION}

Several studies have investigated the role of tranexamic acid in reducing blood loss and improving $\mathrm{Hb}$ in patients undergoing orthopedic surgeries like total knee replacement (TKR), total hip joint replacement (THR), and spine surgeries, but the definitive efficacy has not yet been documented. ${ }^{15,16}$ Fibrinolysis is increased after surgical trauma, therefore increasing intraoperative and postoperative blood loss. Tranexamic acid inhibits fibrinolysis and thus decreases blood loss. The half-life of tranexamic acid is 3 hours and 90 percent excreted by the kidney in 24 hours. In a recent meta-analysis, intraoperative blood loss decreased while performing total knee replacements using intravenous tranexamic acid, without complications thromboembolic events and infection. ${ }^{17}$ In patients with chronic renal failure, cardiac failure, myocardial infarction, history of thromboembolism, neurovascular disorders, and hormone replacement therapy, the chances of thromboembolisms are high while using intravenous tranexamic acid..$^{18} 0$ ne study on 1880 patients reported $24(3.3 \%)$ patients developed symptomatic venous thromboembolism, $16(2.2 \%)$ deep vein thrombosis (DVT), and $8(1.1 \%)$ pulmonary embolism (PE). ${ }^{19}$ Current study observed four cases out of 35 (11.4\%) developed deep vein thrombosis in the intra-venous tranexamic acid Group, and no case was seen in the intra-articular group.

Administration of tranexamic acid intraarticular by flushing the wound or by injection through a suction drain after the closure of the wound will lead to a decrease in the complication associated with intravenous use of tranexamic acid. Previous metaanalyses reported decreased blood loss using intraarticular tranexamic acid in total knee replacements without any complications of thromboembolism..$^{20}$ In this study, a reduced number of blood transfusions (2 blood) in the intra-articular tranexamic acid was observed in the group compared to five blood transfusions in 4 patients in the intravenous group. $W$ hile doing total knee replacements, the efficiency of tranexamic acid to control blood losses is not well established. Conflicting conclusions in different studies while comparing intraarticular and intravenous tranexamic acid results to control bleedings. Previous studies report that the results of intraarticular tranexamic acid are superior to intravenous tranexamic acid. ${ }^{21}$ Sarazeema found a decreased incidence of blood transfusion in patients with intravenous tranexamic acid, relatively high blood transfusion requirements of 50 percent in patients who have not received any form of tranexamic acid. ${ }^{22} \mathrm{~T}$ he need for blood transfusions in patients with total knee replacements is $11 \%$ to $69 \% .23,24$. Li et al. reported that the intravenous tranexamic acid group showed a greater postoperative hemoglobin drop than the IA group. ${ }^{25}$ Similarly, in the current study, the mean variation of $\mathrm{H}$ ct in the intraarticular group was 4.49 and 6.82 in the intra-venous 
tranexamic acid group $(p=0.001)$. In contrast to the above studies, in a review of six randomized controlled and meta-analysis studies in total knee replacements compared results in terms of intraoperative blood losses and number of blood transfusions, the authors did not find any difference between blood transfusions and thromboembolic complications to compare results of intraarticular and intravenous tranexamic acid. ${ }^{26}$

Some discrepancies exist between intravenous and intraarticular administration of tranexamic acid while considering some factors like intramedullary and extramedullary jigs for resections of bone, indications for blood transfusions, use of tourniquets either incomplete procedure or while cementing only, and use of drains. But in our institute, we used a tourniquet before starting the procedure. Operative time in patients with local intraarticular tranexamic acid is approximately 10 minutes more because of a wait after injection intraarticular, but it is without increasing morbidity and has no statistical difference.

There were some limitations in this study related to the small sample size, type of study, and the number of surgeons who operated; four surgeons operated on these patients, all were well experience but with different surgical skills and operative times. In the future, further prospective large cohort and randomized studies are required for providing definitive evidence about the route of tranexamic acid administration in total knee joint arthroplasty.

\section{CONCLUSION}

This study showed that during total knee joint replacement, intra-articular tranexamic acid has high postoperative hemoglobin and hematocrit as compared to the intravenous tranexamic acid group without any increase in thromboembolism. The intra-articular dose of $3 \mathrm{~g}$ of TXA was more efficacious than one-dose (10 $\mathrm{mg} / \mathrm{kg}$ ) IV injection in reducing drained blood loss. W e propose that the intra-articular route may be considered in patients at increased risk of thromboembolism or in whom intravenous tranexamic acid is relatively contraindicated, e.g., renal impairment.

\section{REFERENCES}

1. Bierbaum BE, Callaghan JJ, Galante JO, Rubash $H E$, ToomsRE, W elch RB. An analysis of blood management in patients having a total hip or knee arthroplasty. J Bone Joint Surg [Am] 1999;81:2-10.

2. N oticewala M S, N yce JD, W ang W, G eller JA, M acaulay W . Predicting need for allogeneic transfusion after total knee arthroplasty. J Arthroplasty 2012;27:961-7.

3. Aydın BK, Durgut F, Erkoçak ÖF, Acar MA. Other benefits of intra-articular injection of tranexamic acid in primary total knee arthroplasty apart from reducing blood transfusion rates. E klem $\mathrm{H}$ astalik Cerrahisi 2017;28:25-9.

4. Eubanks JD. Antifibrinolytics in major orthopaedic surgery. J Am Acad O rthop Surg 2010;18:132-8.

5. Dunn CJ, Goa KL. Tranexamic acid: A review of its use in surgery and other indications. D rugs 1999;57:1005-32.

6. Benoni G, Carlsson A, Petersson C, Fredin H. Does tranexamic acid reduce blood loss in knee arthroplasty? Am J K nee Surg. 1995;8:88-92.

7. Lacko M, Cellar R, Schreierova D, Vasko G. Comparison of intravenous and intra-articular tranexamic acid in reducing blood loss in primary total knee replacement. Eklem H astalik Cerrahisi. 2017;28(2):64-71.

8. Peng $H, W$ ang $L, W$ eng $X$, Zhai $J$, L in J, Jin J. Effect of tranexamic acid on symptomatic venous thromboembolism in patients undergoing primary total knee arthroplasty. Arch $\mathrm{M}$ ed Sci. 2020; 16(3): 603-612. DOI: https://doi.org/10.5114/ aoms.2020.92444

9. W ang $S, G$ ao $X, A \cap Y$. T opical versus intravenous tranexamic acid in total knee arthroplasty: a meta-analysis of randomized controlled trials. Int O rthop. 2017;41(4):739-48.

10. Fillingham YA, Ramkumar D B, J evsevar D S, Yates AJ, Shores $P, M$ ullen $K$, et al. T he efficacy of tranexamic acid in total knee arthroplasty: A network meta-analysis. J Arthroplasty. 2018: 33(10):3090-3098.e1.

11. Suresh K. An overview of randomization techniques: An unbiased assessment of outcome in clinical research. J $\mathrm{H}$ um Reprod Sci. 2011;4:8-11.

12. Soni A, Saini R, Gulati A, Paul R, Bhatty S, Rajoli SR. Comparison between intravenous and intra-articular regimens of tranexamic acid in reducing blood loss during total knee arthroplasty. J Arthroplasty 2014;29:1525-7.

13. Gomez-Barrena E, O rtega-Andreu M, Padilla-Eguiluz NG, Pérez-Chrzanowska H, Figueredo-Zalve R. Topical intraarticular compared with intravenous tranexamic acid to reduce blood loss in primary total knee replacement: A doubleblind, randomized, controlled, non inferiority clinical trial. J Bone J oint Surg. 2014;96:1937-44.

14. G eorgiadis AG, M uh SJ, Silverton CD, W eir RM, L aker M W . A prospective double-blind placebo controlled trial of topical tranexamic acid in total knee arthroplasty. J Arthroplasty 2013;28:78-82.

15. Sadigursky D, Araujo LM, Fernandes RJC. Efficacy of tranexamic acid in reducing blood loss in total knee arthroplasty. Acta O rtop Bras. 2018:;26(1):63-66.

16. Oremus $\mathrm{K}$. T ranexamic acid for the reduction of blood loss in total knee arthroplasty. Ann T ransl M ed. 2015:35:2305-5839.

17. W ong J, Abrishami A, El Beheiry H, M ahomed N N, Roderick D avey J, $G$ andhi $R$, et al. T opical application of tranexamic acid reduces postoperative blood loss in total knee arthroplasty: a randomized, controlled trial. J Bone Joint Surg. 2010;92:250313.

18. Ameel $T, W$ est $M$. Tranexamic acid treatment of lifethreatening hematuria in polycystic kidney disease. Int J N ephrol. 2011; D OI: https://doi.org/10.4061/2011/203579

19. Peng $H, W$ ang $L, W$ eng $X$, Z hai J, L in J, Jin J, Q ian W, G ao $\mathrm{N}$. Effect of tranexamic acid on symptomatic venous thromboembolism in patients undergoing primary total knee arthroplasty. Arch M ed Sci. 2020 Jan 19;16(3):603-612.

20. Zhao-Yu C, Yan G, W ei C, Yuejv L, Ying-Ze Z. Reduced blood loss after intra-articular tranexamic acid injection during total knee arthroplasty: a meta-analysis of the literature. Knee Surg Sports T raumatol Arthrosc. 2014;22:3181-90. 
21. Seo JG, Moon YW, Park SH, Kim SM, Ko KR. The comparative efficacies of intra-articular and IV tranexamic acid for reducing blood loss during total knee arthroplasty. Knee Surg Sports T raumatol Arthrosc. 2013;21:1869-74.

22 Sarzaeem M M, Razi M, Kazemian G, M oghaddam M E, Rasi $A M$, Karimi M. Comparing efficacy of three methods of tranexamic acid administration in reducing hemoglobin drop following total knee arthroplasty. J Arthroplasty. 2014;29:15214.

23 Carling M S, Jeppsson A, E riksson BI, Brisby $\mathrm{H}$. T ransfusions and blood loss in total hip and knee arthroplasty: a prospective observational study. J O rthop Surg Res. 2015;10:48.
$24 \mathrm{H}$ amlin BR, DiGioia AM, Plakseychuk AY, Levison TJ. Topical versus intravenous tranexamic acid in total knee arthroplasty. J Arthroplasty 2015;30:384-6.

25 Li J, Liu R, Rai S, Ze R, T ang X, H ong P. Intra-articular vs. intravenous administration: A meta-analysis of tranexamic acid in primary total knee arthroplasty.J Orthop Surg Res: 2020:15:581. D OI: https://doi.org/10.1186/s13018-020-021191

26 Alshryda S, Sukeik M, Sarda P, Blenkinsopp J, H addad FS, $M$ ason JM . A systematic review and meta-analysis of the topical administration of tranexamic acid in total hip and knee replacement. Bone J oint J. 2014;96:1005-15. 